\title{
Türkiye'de Döviz Kurlarının Yurtiçi Fiyatlara Geçiş Etkisi ve Enflasyon Hedeflemesi
}

\author{
Oğuz TÜMTÜRK*
}

\begin{abstract}
$\ddot{O} Z$
Bu çalışmanın amacı, döviz kurunda meydana gelen şokların, Türkiye'deki yurtiçi fiyatlar genel düzeyi üzerindeki etkisinin, enflasyon hedeflemesi öncesi ve sonrasinda nasıl değiştiğini 1994:ml ve 2016:m9 dönemi verilerini kullanarak araştırmaktır. Çalışmada, döviz kuru değişimlerinin yurtiçi fiyatlara geçiş etkisinin enflasyon hedeflemesi ile birlikte azalma eğiliminde olduğu tespit edilmiştir. Döviz kuru geçiş katsayısı, enflasyon hedeflemesi öncesi dönemde 0.64 olarak bulunmuşken, enflasyon hedeflemesi sonrası bu katsayı azalmış ve 0.28 olmuştur. Enflasyon hedeflemesi öncesi ve sonrasinda, hem LCP (yerli para fiyatlamasi) hem de PCP (üretici döviz fiyatlaması) hipotezleri kısa ve uzun dönemde reddedilmiştir. Elde edilen geçiş katsaylsı tahminleri, Türkiye'de döviz kurlarından fiyatlara kısmi geçiş etkisinin varlığın işaret etmektedir. Son olarak, Türkiye'deki enflasyon ataletinin varlığının enflasyon hedeflemesi ile birlikte azaldığı sonucuna ulaşılmıştır.
\end{abstract}

Anahtar Kelimeler: Döviz Kuru Geçiş Etkisi, Enflasyon Hedeflemesi, Yurtiçi Fiyatlar, Türkiye.

JEL Sinıflandırmast: E31, F31

\section{Exchange Rate Pass-Through into Domestic Prices and Inflation Targeting in Turkey}

\begin{abstract}
This article examines exchange rate pass-through into domestic prices in the case of a small emerging open market economy such as Turkey before and after the adoption of inflation targeting using monthly data over the period of 1994:ml and 2016:m9. After the adoption of inflation targeting, empirical findings first reveal that pass-through from exchange rates to domestic inflation has substantially weakened. In the long run, the exchange rate pass-through impact on domestic prices is 0.64 before the inflation targeting while the pass-through rate is 0.28 after the inflation targeting. Second, the validity of LCP (local currency pricing) and PCP (producer currency pricing) hyphotheses are rejected before and after the adoption of inflation targeting both short run and long run. The estimates of the pass-through coefficients give support for incomplete pass-through into domestic prices. Finally, a more inflationary-focused policy helps to reduce the inflation inertia in Turkey.
\end{abstract}

Keywords: Exchange Rate Pass-Through, Inflation Targeting, Domestic Prices, Turkey.

JEL Classification: E31, F31

\footnotetext{
* Yrd. Doç. Dr., Ordu Üniversitesi, Ünye İktisadi ve İdari Bilimler Fakültesi, İktisat Bölümü, oguz.tumturk@gmail.com
} 


\section{GİRIŞ}

Döviz kurları, özellikle gelişmekte olan ülkelerde, çok uzun yıllardan beri makroekonomik politika tartışmalarının tam merkezindedir. Bunun en büyük nedeni ise, döviz kurlarında meydana gelen değişmelerin ekonomide çok sayıda değişken üzerinde etkili olabilmesidir. Özellikle Türkiye gibi daha çok ihracat yapmak için daha çok ithalat yapmak zorunda olan ülkelerde ise, döviz kurlarında meydana gelen şokların ekonomide daha büyük etkiler yaratması beklenmektedir. $\mathrm{Bu}$ etkilerden biri de döviz kurundaki değişmelerin yurtiçi fiyatlar üzerindeki etkisidir. İktisatçılar, kur şokları ve yurtiçi fiyatlar arasındaki ilişkiyi "döviz kurunun geçiş etkisi (exchange rate pass through)" kavramı ile açıklamaktadır. Bu kavram kısaca döviz kurunda meydana gelen yüzde 1 değişimin, yurtiçi genel fiyatlar düzeyi üzerinde yaratığı yüzde değişimi ifade etmektedir.

İktisat literatüründe, döviz kurlarındaki şokların çeşitli ülkeler için geçiş etkisini ölçen çok sayıda çalışma vardır. Bu çalışmaların pek çoğu, sözkonusu geçiş etkisinin özellikle 1990'larla birlikte azalma eğilimine girdiğine dair sonuçlara ulaşmışlardır. Taylor (2000)'a göre döviz kuru geçiş etkisinin 1990'lı yıllarda azalmasının nedeni, enflasyonun pek çok ülkede uygulanan para politikaları yoluyla düşmeye başlamasından kaynaklanmaktadır. Taylor'un bu çalışmasıyla birlikte, onun bu hipotezini test etmek için çok sayıda makale yayınlanmıştır. $\mathrm{Bu}$ makalelerden bazıları, Taylor'un hipotezini üzellikle enflasyon hedeflemesine geçiş dönemleri ile birlikte değerlendirip, döviz kuru geçiş etkisinin enflasyon hedeflemesi ile nasıl değiştiğini araştırmışlardır. Literatürdeki genel kanı ise enflasyon hedeflemesi ile birlikte geçiş katsayılarının düşeceği yönünde olmuştur. Bu çalışmanın başlıca amacı, Türkiye'de döviz kuru geçiş etkisini analiz etmek ve özellikle enflasyon hedeflemesi ile birlikte geçiş katsayılarında nasıl bir değişim olduğunu incelemektir. Bu noktadan hareketle, öncelikle 1994-2016 dönemi bütünüyle ele alınıp analiz edilecektir. Bu aşamada, döviz kuru değişmelerinin hem genel fiyatlar düzeyi hem de maden, imalat, enerji gibi sanayi alt kolları fiyatları üzerinde yarattığı geçiş etkileri incelenecektir. Bunu yaparken 1994-2016 dönemi boyunca uygulanan para politikası stratejileri hiç değişmemiş gibi hareket edilecek ve ortalama bir geçiş katsayısı tahmin edilecektir. Daha sonra bu varsayım kaldırılacak ve uygulanan para politikası staratejilerindeki değişikliklerin yapısal olmayan parametreleri de zaman içinde değiştirebileceği varsayımından hareketle, yeni bir para politikası stratejisi olarak açık enflasyon hedeflemesine geçildiği 2006 yılı öncesi ve sonrasında geçiş katsayılarının nasıl etkilendiği analiz edilmeye çalışılacaktır. Ayrıca, enflasyon ataleti (inlation inertia) kavramı da analize dahil edilecek ve enflasyon ataletinin de enflasyon hedeflemesi ile birlikte değişimi analiz edilecektir.

Bunlara ek olarak, literatürdeki yaygın tartışmalardan birine daha giriş yapılacaktır. Bu tartışma, herhangi bir döviz kuru şoku nedeniyle yurtiçi fiyatlar genel düzeyinin ne düzeyde etkileneceği araştırılırken, fiyatlamanın yerli para fiyatlamasına (local currency pricing (LCP)) bağlı olarak mı yoksa üretici döviz 
fiyatlamasına (producer currency pricing (PCP)) bağlı olarak mı gerçekleşeceği tartışmasıdır. LCP ve PCP hipotezleri, oluşan döviz kuru şokları sonucu yurtiçi fiyatlarında meydana gelen değişimlerin düzeyini ifade eder. LCP hipotezine göre, döviz kurlarında meydana gelen değişimlerin yurtiçi fiyat elastikiyeti " 0 " olurken (sıfır geçiş etkisi-zero pass through), PCP'de ise "1" olacaktır (tam geçiş etkisicomplete pass through). Ancak, pratikte kısa ve uzun dönem tahminler genelde sifır ile bir arasında değişecek ve kısmi geçiş etkisinden (incomplete pass-through) söz edilecektir. Bu çalışmada da, Türkiye'deki geçiş etkisinin düzeyi analiz edilirken, LCP ve PCP hipotezlerinin geçerliliği test edilecektir.

Bu çalışma 7 ana bölümden oluşmaktadır. Takip eden bölümde, geçiş etkilerini hem uluslarası düzeyde hem de ulusal düzeyde inceleyen çalışmalara yer verilecektir. Üçüncü ve dördüncü bölümde sırası ile ön analiz sonuçları ve çalışmada kullanılacak teorik model ile tahmin yöntemi hakkında bilgi verilirken, beşinci bölümde veri setinden bahsedilecektir. Altıcı bölümde ise modelin hem tüm örneklem dönemi boyunca hem de enflasyon hedeflemesi öncesi ve sonrasındaki tahmin sonuçları paylaşılacaktır. Çalışma, son bölümde yer alan sonuç ve öneriler ile sonlandırilacaktır.

\section{LITERATÜR İNCELEMESI}

Literatürde, döviz kurundaki şokların yurtiçi fiyatlara geçiş etkisini araştıran çok sayıda çalışma vardır. Bu bölümde, hem genel olarak döviz kuru geçiş etkilerini araştıran çalışmalar, hem de enflasyon hedeflemesi ile birlikte sözkonusu geçiş katsayılarının ne yönde değiştiğini araştıran çalışmalar hakkında bilgi verilecektir.

Gagnon ve Ihrig (2004) döviz kuru geçiş etkisini 1971-2003 yılları arasında 20 gelişmiş ülke için test etmiş ve tahmin edilen geçiş katsayıları ile enflasyon değişkenliği arasında anlamlı bir ilişki bulmuşlardır. Ayrıca, döviz kuru değişmelerinin ülke içi fiyatlara geçiş etkisinin 1980'lerle birlikte azalma eğilimine girdiğini belirtmişlerdir. Campa ve Goldberg (2005), 23 OECD ülkesi için 19752003 yılları arasını kapsayan çalışmalarında, döviz kuru değişmelerinin ithal fiyatları üzerindeki geçiş etkisini analiz etmişlerdir. Özellikle kısa dönemde, sözkonusu ülkelerin imalat sektörlerinde kısmi geçiş etkisinin varlığına işaret etmişlerdir. Uzun dönemde ise, ithal mallarının pek çoğunda tam geçiş etkisinin varlığını tespit etmişlerdir. Ayrıca, döviz kuru oynaklığının ve enflasyon değişkenliğinin yüksek olduğu ülkelerde döviz kuru geçiş elastikiyetleri daha yüksek bulunmuştur. Son olarak, ele alınan analiz döneminde ithal fiyatları üzerindeki ortalama geçiş etkisi kısa dönem için 0.46 uzun dönem için ise 0.64 olarak hesaplanmıştır. Edwards (2006), yedi ülke (Avustralya, Brezilya, Kanada, Şili, Kore, Meksika, İsrail) için 1985-2005 yılları arasında çeyreklik veri seti kullanarak yaptığı çalışmada, enflasyon hedeflemesi ile birlikte geçiş katsayılarının düştüğü sonucuna varmıştır. Ayrıca, enflasyon hedeflemesi ile birlikte enflasyon ataletinin Meksika, Kanada ve Australya'da anlamlı olarak azaldığını da göstermiş̧lerdir. Junior (2007) ise Kanada, İngiltere, İsveç, Bezilya, Çek 
Cumhuriyeti, Güney Afrika, Meksika ve Kuzey Kore ülkeleri için ARDL modeli kullanarak yaptığı çalışmada, benzer sonuca ulaşmıştır.

Choudhria ve Hakura (2006), Taylor (2000) tarafından ortaya atılan düşük enflasyon ortamının daha düşük bir döviz kuru geçiş etkisine neden olacağına dair hipotezini 1979-2000 yılları arasında 79 ülke için test etmişlerdir. Döviz kuru geçiş etkisi ve enflasyon arasında güçlü ve pozitif yönde bir ilişki olduğu sonucuna varmışlardır. Ito ve Sato (2007), 1990'lı yıllarda döviz krizi yaşayan 8 ülkeyi (Türkiye, Endonezya, Meksika, Tayland, Malezya, Güney Kore, Brezilya ve Arjantin) kullanarak yaptıkları çalışmada, 1990-2006 dönemleri arasında döviz kuru geçiş etkisini incelemişlerdir. Analiz sonuçları, Latin Amerika ülkelerindeki geçiş etkisinin Türkiye ve diğer Asya ülkelerinden (Endonezya hariç) daha yüksek olduğunu göstermiştir. Mccarthy (2007), dokuz gelişmiş ülkenin VAR modeli ile döviz kuru ve ithalat fiyatlarının üretici ve tüketici fiyatları üzerindeki etkisini araştırmıştır. Etki tepki fonksiyonları, döviz kurundaki şokların enflasyon üzerindeki etkisinin analize konu olan ülkelerin pekçoğunda sınırlı etkiye sahip olduğunu göstermiştir. Geçiş katsayıları özellikle ithalat eğilimi yüksek ülkelerde daha yüksek bulunmuştur. Masha ve Park (2012), 1994-2010 arasında Maldivler için yaptıkları çalışmada, düviz kuru geçiş elastikiyetlerini hem üretici hem de tüketici fiyatları için test etmişlerdir. Elde edilen sonuçlar, döviz kurunun fiyatlar üzerindeki geçiş etkisinin anlamlı olduğunu göstermekle birlikte, tam geçiş etkisi tespit edilememiştir. Sweidan (2013), Ürdün için 1976-2011 yıllarını kapsayan çalışmasında döviz kuru geçiş elastikiyetini 0.13 olarak bulmuştur. Ancak, Ürdün için hem kısa hem de uzun dönemde tam geçiş etkisi bulunamamıştır. Ayrıca, petrol fiyatlarının Ürdün'ün ithal fiyatları üzerindeki etkisi, döviz kurundaki değişmelerden kaynaklanan fiyat etkisinden çok daha büyük olmuştur. Jiang ve Kim (2013), 1999-2009 yılları arasında Çin için yaptıkları ve Structural Vector Autoregression (SVAR) yöntemini kullandıkları çalışmalarında, döviz kuru şoklarının üretici fiyatları üzerindeki geçiş etkisinin tam olmadığ sonucuna ulaşmışlardır. Mujico ve Saens (2015), ise 1986-2009 yılları arasında çeyreklik veriler kullanılarak Şili için yaptıkları çalışmada, enflasyon hedeflemesi ile birlikte geçiş katsayılarının azaldığı sonucuna ulaşmışlardır.

Literatürde döviz kuru geçiş etkisini Türkiye özelinde araştıran yine çok sayıda çalışma mevcuttur. Leigh ve Rossi (2002), 1994-2002 dönemi verilerini kullanarak yaptıkları çalışmada, döviz kuru değişmeleri ve yurtiçi fiyatlar arasındaki ilişkiyi araştırmışlardır. Elde edilen sonuçlara göre döviz kuru değişimlerinin fiyatlara geçiş etkisi yaklaşık bir yılda tamamlanmakta, fakat bu geçiş büyük ölçüde ilk dört ayda ortaya çıkmaktadır. Ayrica, döviz kurundan toptan eşya fiyatlarına geçiş, döviz kurundan tüketici fiyatlarına geçişe göre daha güçlüdür. Volkan, Saatçioğlu, Korap (2007), Türkiye'de döviz kurundan fiyatlara geçiş etkisini 2003 yılı öncesi ve sonrası olmak üzere iki ayrı dönemde büyüklük bakımından incelemişler ve 2003 yılı sonrasında geçiş etkisinin azaldığını gözlemlemişlerdir. Kara ve Ögünç (2008), VAR (Vector Autoregression) yöntemi 
kullanarak Türkiye için yaptıkları çalışmada, enflasyon hedeflemesinin uygulanması ile birlikte döviz kuru şoklarının enflasyon üzerindeki etkilerinin önemli ölçüde azaldığı sonucuna ulaşmışlardır. Tekin ve Yazgan (2009), 19882004 dönemini kapsayan ve VECM (Vector Error Correction Model) modeli kullandıkları çalışmalarında, literatürden farklı olarak imalat sektöründeki ihracat fiyatları üzerinde tam geçiş etkisini tespit ederlerken, ithalat fiyatları üzerinde tam geçiş etkisini tespit edememişlerdir. İhracat fiyatlarında tam geçiş etkisinin nedenini ise imalat sektöründeki yerel şirketlerin rekabet gücünün yüksekliği ile açıklamışlardır. Yine Kara ve Öğünç (2012), VAR model kullanarak 2002-2011 dönemini kapsayan çalışmalarında, Türkiye'de döviz kuru ve ithalat fiyatlarının çekirdek tüketici fiyatları üzerindeki geçişkenlik etkisini incelemişlerdir. Tahmin sonuçları, geçişkenliğin bir yıllık zaman diliminde ortalama yüzde 15 civarında olduğuna işaret etmektedir. Ayrıca gerek VAR sonuçları, gerekse zaman içinde değişen parametre modeli ile elde edilen sonuçlar, döviz kuru ile tüketici fiyatları arasındaki ilişkinin azalmaya devam ettiğini göstermektedir Altıntaş (2014), Türkiye'de 1987-2011 dönemi üç aylık verileriyle döviz kurunun fiyatlar üzerindeki geçiş etkisini ARDL yöntemi ile tahmin etmiştir.

Özdamar (2015), 2006-2015 dönemi için ARDL-Sınır testi yöntemi kullanılarak yaptığı çalışmada, yurt içi üretici fiyatları üzerinde döviz kuru etkisinin enflasyon hedeflemesi döneminde düşük olduğunu göstermiştir. Çalışmada, Goldberg ve Knetter (1997), Campa ve Goldberg (2005), Ghosh ve Rajan (2007) tarafindan kullanılan üç model esas alınmıştır. ARDL modeli tahmini sonucunda uzun dönemde döviz kurunun yurtiçi fiyat elastikiyeti sırasıyla $0.91,0.85$ ve 0.72 olarak bulunmuştur. Ergin (2015), yaptığı çalışmada Türkiye'de döviz kuru ve enflasyon arasındaki ilişkiyi VAR analizi kullanarak 2005-2014 dönemi için incelemiştir. Modelin tahmini sonucunda, döviz kuru hareketlerinin yurtiçi fiyatları üzerindeki geçişkenliğinin örneklem dönemi başında daha güçlü olduğu, bu etkinin örneklem dönemi boyunca ise giderek zayıfladığı sonucuna ulaşılmıştır. Diğer taraftan, Bayat, Özcan ve Taş (2015), 2003-2013 yıllarını kapsayan çalışmalarında, enflasyon hedeflemesi stratejisi ile birlikte dalgalı kur politikasının uygulanmasının döviz kurlarına istikrar kazandırdığını ve bu nedenle Türkiye ekonomisinde döviz kuru geçiş etkisinin olmadığ sonucuna ulaşmışlardır. Alptekin, Yılmaz ve Taş (2016), VAR modeli kullanarak döviz kurunun üretici ve tüketici fiyatlan üzerindeki geçiş etkisini Türkiye için 2005- 2015 dönemleri arasinda test etmişlerdir. Yapılan analizde, geçişkenliğin fiyatlar üzerine etkisi tüketici fiyat endeksi (TÜFE) ve üretici fiyat endeksi (ÜFE) için ayrı ayrı hesaplanmıştır. Çalışmada, döviz kurundan tüketici fiyatlarına geçiş etkisinin azalma eğiliminde olduğu tespit edilmiştir. Döviz kurundaki bir birimlik şoka tüketici fiyatlarının verdiği tepkinin üretici fiyatlarına verdiği tepkiye göre daha düşük olduğu gözlemlenmiştir. 


\section{II. ÖN ANALIZZ SONUÇLARI VE MODEL}

$\mathrm{Bu}$ bölümde, çalışmada kullanılan model ve bu modele ilişkin tahmin değerlerini paylaşmadan önce döviz kurları ve enflasyon arasındaki ilişki kabaca gözlemlenmeye çalışılacaktır. Döviz kurundaki şokların enflasyona geçiş katsayıların ${ }^{1}$ görebilmenin en basit yötemlerinden biri kayan pencereler (rolling windows) yöntemini kullanmak olabilir. Bunun için döviz kurundaki logaritmik değişimler ile fiyatlar düzeyindeki logaritmik değişmelerin basit regresyonu kullanılacaktır.

Grafik 1, kayan pencereler durumunda elde edilen tahmin sonuçlarınının değerlerini göstermektedir. Kayan pencereler yönteminde 85 aydan oluşan bir pencere dönemi kullanılırken, bundaki amaç özellikle 2001 krizi sonrasını gözlemleyebilmektir. Grafik 1'den görüldüğü üzere, döviz kurundaki şokların fiyatlar üzerindeki etkisi, özellikle 2007 yılı ve sonrasında değişmekte ve etki gözle görülür şekilde azalmaktadır. Buradan çıkan ilk izlenim, Türkiye açık enflasyon hedeflemesine geçtikten sonra (2006 ve sonrası) kurlardan fiyatlara olan geçiş katsayılarında literatürde de tartışıldığu üzere azalma olduğu yönündedir. Ayrıca, Şubat 2001 ekonomik krizinin başlangıcında TL'nin büyük oranda değer kaybetmesi sonucu oldukça yükselen geçiş katsayıları, 2001 yılı sonuna doğru önemli ölçüde bir azalma göstermektedir.

Grafik 1: Yurtiçi Fiyatlar üzerindeki Geçiş Etkisi, Kayan Pencereler

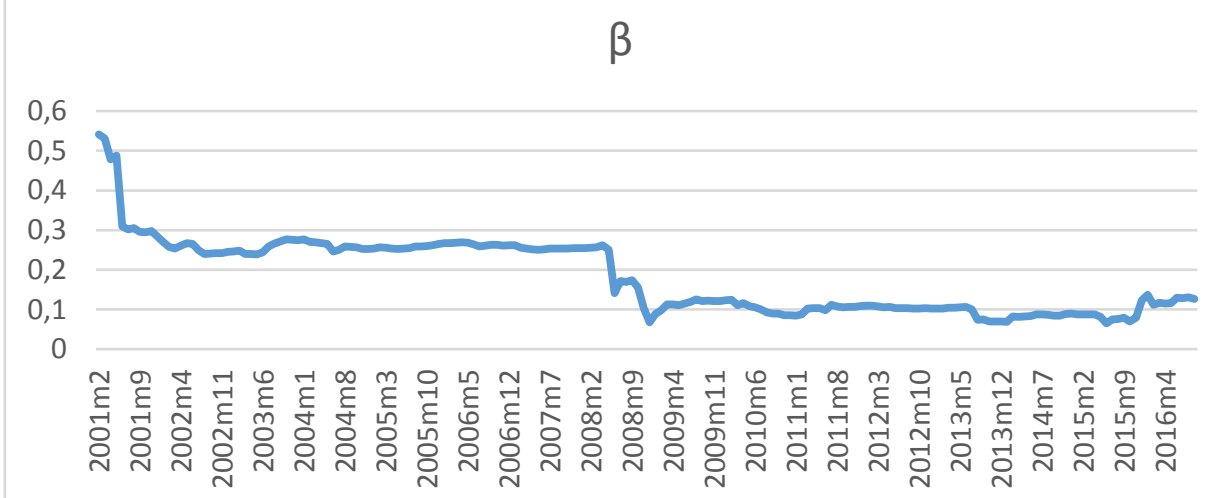

Not: Burada $\beta$ tahmin katsayıları 85 aylık bir pencere dönemi kullanılarak elde edilen basit regresyon sonuçlarıdır.

Şimdi de, döviz kurundaki değişimler ile fiyat düzeyinde meydana gelen değişmeler arasındaki korelasyon katsayılarına bakalım. Tablo 1, sözkonusu korelasyon katsayılarını vermektedir. 1994: $\mathrm{m}_{1}-2016: \mathrm{m}_{9}$ arasındaki korelasyon katsayıs 0.70 iken, 1994: $\mathrm{m}_{2}-2005: \mathrm{m}_{12}$ aras1 korelasyon katsayıs1 0.76 ve 2006: $\mathrm{m}_{1}$ 2016:m9 arası korelasyon katsayısı 0.37'dir. Yani, fiyat değişimleri ile kur

\footnotetext{
${ }^{1} \mathrm{Bu}$ aşamada, ileride kullanılacak model ile tutarlı olması açısından nominal döviz kuru olarak ABD Doları/TL döviz kuru, fiyat endeksi olarak ise ÜFE kullanılmıștır.
} 
değişimleri arasındaki pozitif yönde doğrusal ilişki, enflasyon hedeflemesi birlikte azalmıştır.

Tablo 1: Döviz Kuru ve Yurtiçi Fiyatlar Değişimi, Korelasyon Katsayıları

\begin{tabular}{|c|c|}
\hline Dönemler & Korelasyon Katsayıları \\
\hline 1994:M2-2016:M9 & 0.70 \\
\hline 2094:M2-2005:M12 & 0.76 \\
\hline
\end{tabular}

Eldeki bu verilerden hareketle, kabaca enflasyon hedeflemesi ile birlikte döviz kuru geçiş etkisinin zayıflama eğiliminde olabileceği şeklinde bir önermede bulunulabilir. Ancak, bu sözkonusu bulgular hiçbir teorik modele dayanmamaktadır. Ayrıca kayan pencereler analizinin bize verdiği sonuçlar seçilen pencere uzunluğuna dayalı olarak değişebilecektir. Bu nedenlerle, geçiş etkisinin gerek tüm örneklem dönemi boyunca gerekse enflasyon hedeflemesi ve sonrası dönemde davranışlarını daha iyi analiz edebilmek için Campa ve Goldberg (2005) tarafindan önerilen ve literatürede geniş kabul gören modelden yararlanılacaktır. Literatürdeki ampirik çalışmaların pek çoğu da Campa ve Goldberg ${ }^{2}$ tarafından önerilen aşağıdaki modelin çeşitli varyasyonlarını kullanmaktadır:

$$
\Delta p_{t}=\gamma+\sum_{i=0}^{n} a_{i} \Delta e_{t-i}+\sum_{i=0}^{n} b_{i} \Delta p_{t-j}^{*}+c \Delta y_{t}+u_{t}
$$

Burada $p_{t}$, ithalatçı ülke yurtiçi fiyat endeksini, $e_{t}$ nominal döviz kurunu, $\mathrm{p}_{\mathrm{t}}{ }^{*}$ dünya fiyatlarını ve son olarak $\mathrm{y}_{\mathrm{t}}$ ithalatçı ülke için GSYİH değerini göstermektir. $u_{t}$ ise standart özelliklere sahip hata terimidir. Ayrica, tüm değişkenlerin logaritmik dönüşümü yapılmıştır. Burada $a_{0}$ tahmin edilen kısa dönem geçiş katsayısını gösterirken, $\sum_{i=0}^{n} a_{i}$ ise uzun dönem geçiş katsayısını göstermektedir. Literatürde genellikle 3 veya 4 çeyreklik n gecikme değerleri kullanılmaktadır. Örneğin, Campa ve Goldberg (2005) yaptıkları çalışmada çeyreklik verileri kullanmış olup, $\mathrm{n}=4$ olarak belirlenmiştir. Benzer şekilde, Edwards (2006) yaptığı çalışmada, yedi ülke için çeyreklik veriler kullanmış ve ülkelerin pek çoğu için $n=4$ olarak kullanılmıştır.

$\mathrm{Bu}$ modelin kullanılmasındaki amaçlardan biri de, literatürdeki üretici döviz fiyatlamasına karşılık yerel para fiyatlaması tartışmasına girilebilmesine de olanak sağlayacak olmasındadır. Yerli para fiyatlamasının (LCP) geçerli olduğu durumlarda fiyatlar ithalatçı ülke yerel para birimine göre belirlenmektedir. Bunu daha açık bir şekilde ifade edebilmek için ithalatçı A ülkesinin yerli parasının değer kaybettiği varsayımından yola çıkalım. B ülkesi ise ihracat yapan ülke olsun. A ülkesinde ithal malına olan talep azalacağından dolayı B ülkesindeki ihracatçı firmalar, A ülkesinde ithal mallara rakip yerli malı talebinin artacağını düşünecektir. Bu durumda B ülkesindeki ihracatçı firmalar pazar payını koruyup A ülkesindeki yeni girişleri engellemek amacıyla, kar marjlarından feragat edip döviz kurundaki değişimleri tamamen sönümleyecek ve mal fiyatlamasında A ülkesi para

\footnotetext{
${ }^{2}$ Modelin ayrıntıları için Campa ve Goldberg (2005)'e bakılabilir.
} 
birimini kullanmayı tercih edebilecektir. Böylece döviz kuru değişimlerinin A ülkesi iç fiyatlarına geçiş etkisi "sıfır" olacaktır'. Diğer taraftan, üretici-döviz fiyatlaması (PCP) ise fiyatların ihracatçı ülkenin döviz kuruna göre ayarlanmasını ifade eder. $\mathrm{Bu}$ durumda, tek fiyat kanunu gereği, nominal döviz kurundaki değişmeler yerel ülkedeki ithal mallarına birebir yansıyacaktır. Bu da literatürde, tam geçiş etkisi olarak ifade edilmektedir. Özellikle gelişmekte olan ülkelerde, bağımsızlığını kaybeden veya böyle bir algı yaratan merkez bankalarının, azalan güvenilirlikleri ile birlikte iktisadi karar birimlerinin beklentilerini arzu edilen enflasyon oranına paralel olarak yönetememesi durumunda, "fiyatların döviz kuruna endekslenmesi" eğilimi de geçiş etkisinin düzeyini arttıracak ve PCP hipotezinin varlığını güçlendirebilecektir.

\section{III.TAHMIN YÖNTEMI}

Bu çalışmada regresyon (1)'i tahmin etmek için klasik EKK yöntemi kullanılacaktır. Eğer regresyon (1)' de yer alan birinci farkları alınan değişkenler durağan (stationary) ise bu durumda klasik EKK yöntemini kullanmanın bir sakıncas1 olmayacak ve sahte regresyon (spurious regression) sorunu ile karşılaşılmayacaktır. Farkları alınmış değişkenlerin durağanlık düzeyini araştırmak için literatürde oldukça yaygın olarak kullanılan Augmented Dickey Fuller (ADF) (1979) ve Phillips-Perron (1989) birim kök testleri uygulanacaktır. Dickey ve Fuller (1979) herhangi bir zaman serisi $\mathrm{z}_{\mathrm{t}}$ 'nin birim köke sahip olup olmadığını test etmek için aşağıdaki modeli kullanmışlardır:

$$
\Delta z_{t}=\Phi+\psi z_{t-1}+\omega t+\sum_{j=1}^{k} \gamma_{j} \Delta z_{t-j}+\rho_{t}
$$

Burada $\mathrm{k}$, modelde kullanılan gecikme sayısını, $\mathrm{t}$ ise zaman trendini ifade etmektedir. ADF testi regresyon (2)'nin tahminine dayanmakta ve her bir serinin birim köke sahip olduğunu ifade eden yokluk hipotezi $\mathrm{H}_{0}: \psi=0$ iken, alternatif hipotez $\mathrm{H}_{\mathrm{a}}: \psi \neq 0$ olup serinin durağan olduğunu belirtir. ADF testine ek olarak, Phillips-Perron (1989) testi kullanılmasının nedeni ise, muhtemel bir otokorelasyon ve/veya eşvaryans problemine karşı kovaryans matrisinde uyarlama yapan NeweyWest standart hatalarını kullanabilmektir. Her iki test sonucu da regresyon (2)'nin sabit ve trend içerip içermemesine göre farklı sonuçlar verebilmektedir. Dolayısıyla, test sonuçları "trend ve sabit", "sabit" ve" hiçbiri" alternatif durumlarına göre verilecektir.

Bununla birlikte analiz dönemi oldukça uzun bir dönemi kapsadığından, tek içsel (endogeneous) yapısal kırılmayı gözönüne alan Zivot ve Andrews (1992) Testi ile iki yapısal kırılmayı yine içsel olarak gözönüne alan Clemente, Montanes ve Reyes (1998) Testi kullanılacaktır. Zivot ve Andrews Testi içsel kırılma yılını, ADF test istatistiğinin minimum olduğu dönem olarak belirler. Öte yandan Clemente, Montanes ve Reyes testi serilerin birim kök analizlerinin yaparken iki model kullanır. Bunlardan ilki trend değişkeninde kırılma olduğunu varsayan

\footnotetext{
${ }^{3}$ Bununla birlikte, pratikte birçok ülke örneğinde de daha sık görülen durum, ihracatçı firmaların piyasaya yeni girişleri engelleyebilmek amacıyla kar marjlarını uyarlayıp döviz kurundaki değişimleri kısmi olarak A ülkesi fiyatlarına yansitmalarıdır.
} 
Additive Outlier Model (AO); diğeri ise hem trend hem de sabitte kırılma olduğunu varsayan Innovational Outlier Model (IO) olarak da bilinen modeldir.

Regresyon (1) tahmin edilirken literatürde karşılaşılan problemlerin başlıcası muhtemel bir içsellik (endogeneity) problemidir. Diğer bir değişle, $\Delta e_{t}$ ile hata terimi $u_{t}$ arasinda korelasyon olabilme ihtimalidir. Bu durumda, bu sorunu ortadan kaldırmak için kullanılan yöntemlerin (iki aşamalı en küçük kareler yöntemi gibi) en büyük zorluğu, $\Delta e_{t}$ 'yi temsil için kullanılacak bir değişken (ki bu değişken $\Delta e_{t}$ ile bir korelasyona sahipken hata terimi ile arasında bir korelasyona olmamalidır) bulmanın zorluğudur. Potansiyel içsellik problemine rağmen, Campa ve Goldberg (2005), Gagnon ve Ihrig (2004)'in de içinde bulunduğu pek çok çalışma, tahmin yöntemi olarak en küçük kareler yöntemini güvenilir bulmuşlardır.

\section{VERI SETI}

$\mathrm{Bu}$ çalışmanın veri seti 1994:m $\mathrm{m}_{1}-2016: \mathrm{m}_{9}$ dönemini kapsamaktadır. Türkiye'deki yurtiçi fiyatlar için ÜFE kullanılmış olup Amerikan Merkez Bankası (FRED) internet sitesinden elde edilmiştir. Çalışmada ÜFE endeksinin kullanılmasının iki nedeni vardır. Bunlardan ilki, literatürde genel olarak belirtildiği üzere, döviz kurundaki değişmenin fiyatlara etkisi TÜFE üzerinden sinırlı olabilmektedir (Edwards (2006), Leigh ve Rossi (2002), Junior (2007), Arslaner, Karaman, Arslaner, Kal (2007). İkincisi ise, ÜFE endeksini kullanarak ÜFE'nin kapsamındaki sanayi alt sektörlerinde (Madencilik, İmalat ve Enerji) de geçiş etkisinin incelenmesi amaçlanmaktadır. Dünya fiyatlarını temsilen Edwards (2006)'ın önerisi takip edilmiş ve FRED'den elde edilen ABD Üretici Fiyatları Endeksi (Producer Price Index (PPI)) kullanılmıştır. Nominal döviz kuru (Amerikan Doları/TL) ise TCMB internet sitesinden elde edilmiş olup, döviz kurundaki yükselme TL'nin değer kaybetmesi anlamına gelmektedir. Döviz kuru olarak ABD Doları/TL nominal döviz kuru kullanılmasinin nedeni, ABD dolarının Türkiye dış ticaretindeki ağırlığından kaynaklanmaktadır. Türkiye için aylık GSYIH değişkenini temsilen ise aylık sanayi üretim endeksi kullanılacaktır ve sözkonusu veri seti OECD'den elde edilmiştir. ÜFE kapsamındaki sanayi altkollarına ait fiyat endeksleri de (imalat, madencilik ve enerji) yine TCMB'den elde edilmiştir.

\section{V.MODEL TAHMINI}

\section{A.1994-2016 Dönemi}

Bu bölümde, 1994-2016 dönemi boyunca aynı para politikası stratejisi uygulanmış gibi hareket edilerek, döviz kuru değişmelerinin hem genel fiyatlar düzeyi hem de maden, imalat, enerji gibi sanayi alt kolları fiyatları üzerinde yarattığı ortalama geçiş etkisi tahmin edilecektir.

Tablo 2, Augmented Dickey-Fuller (ADF) (1979) ve Phillips-Perron (1989) birim kök test sonuçlarını göstermektedir. Her iki test sonucu da modelde kullanılan birinci farkı alınmış değişkenlerin \%5 hata payı ile birim köke sahip olmadıklarını göstermektedir. Dolayısıyla, modelin tahmininde klasik EKK yöntemini kullanmanın bir sakıncası yoktur. Tablo 3 ve 4 ise sırasıyla tek ve iki 
yapısal kırılmanın içsel olarak belirlendiği Zivot ve Andrews (1992) Testi ile Clemente, Montanes, and Reyes (1998) birim kök testleri sonuçlarını göstermektedir. Her iki testten elde edilen sonuçlar da değişkenlerin birim köke sahip olduğunu belirten yokluk hipotezinin tüm değişkenler için $\% 5$ hata düzeyinde reddedildiğini göstermektedir. Diğer bir değişle yapısal kırılmaların gözönüne alındığı veya alınmadığı tüm durumlarda, birinci farkları alınmış serilerin durağan olduğu sonucuna ulaşılmıştır.

Tablo 2: Birim Kök Test Sonuçları

\begin{tabular}{|c|c|c|}
\hline$\Delta \mathbf{p}_{\mathbf{t}}$ & $\begin{array}{c}\text { ADF Test İstatistiği } \\
\text { [\%5 Kritik Değerler] }\end{array}$ & $\begin{array}{c}\text { Phillips-Perron Test İstatistiği } \\
\text { [\%5 Kritik Değerler] }\end{array}$ \\
\hline Trend ve Sabit & $-3.750[-3.430]$ & $-9.673[-3.429]$ \\
\hline Sabit & $-2.648[-1.651]$ & $-7.089[-2.879]$ \\
\hline Hiçbiri & $-2.556[-1.950]$ & $-5.393[-1.950]$ \\
\hline \multicolumn{3}{|l|}{$\Delta \mathbf{p}_{\mathbf{t}}^{*}$} \\
\hline Trend ve Sabit & $-6.913[-3.429]$ & $-11.095[-3.42]$ \\
\hline Sabit & $-6.890[-1.651]$ & $-11.094[-2.879]$ \\
\hline Hiçbiri & $-6.652[-1.950]$ & $-10.954[-1.950]$ \\
\hline \multicolumn{3}{|l|}{$\Delta \mathbf{e}_{\mathrm{t}}$} \\
\hline Trend ve Sabit & $-5.023[-3.429]$ & $-10.699[-3.429]$ \\
\hline Sabit & $-4.266[-1.651]$ & $-10.005[-2.879]$ \\
\hline Hiçbiri & $-3.597[-1.950]$ & $-9.186[-1.950]$ \\
\hline \multicolumn{3}{|l|}{$\Delta \mathbf{y}_{\mathbf{t}}$} \\
\hline Trend ve Sabit & $-6.512[-3.429]$ & $-30.450[-3.429]$ \\
\hline Sabit & $-6.487[-1.651]$ & $-30.497[-2.879]$ \\
\hline Hiçbiri & $-6.014[-1.950]$ & $-29.724[-1.950]$ \\
\hline
\end{tabular}

Not: Gecikme uzunlukları belirlenirken Akaike (1973) Information Criteria (AIC) kullanılmıştır. $\Delta \mathrm{p}_{\mathrm{t}}$ için $11, \Delta \mathrm{p}_{\mathrm{t}} *$ için $5, \Delta \mathrm{e}_{\mathrm{t}}$ için $6, \Delta \mathrm{y}_{\mathrm{t}}$ için 2 gecikme uzunluğu kullanılmıştır. 
Tablo 3: Zivot ve Andrews Test Sonuçları

\begin{tabular}{|c|c|c|c|c|}
\hline$\Delta \mathbf{p}_{\mathbf{t}}$ & $\begin{array}{l}\text { Gecikme } \\
\text { Uzunluğu }\end{array}$ & Minimum T-Stat & $\begin{array}{l}\text { \%5 Kritik } \\
\text { Değerler }\end{array}$ & Kırılma Y1lı \\
\hline Trend ve Sabit & 1 & -9.88 & -5.08 & $2003 m_{4}$ \\
\hline Sabit & 1 & -9.48 & -4.80 & $2002 \mathrm{~m}_{2}$ \\
\hline Trend & 1 & -9.63 & -4.42 & $2005 \mathrm{~m}_{7}$ \\
\hline \multicolumn{5}{|l|}{$\Delta \mathbf{p}_{\mathbf{t}}^{*}$} \\
\hline Trend ve Sabit & 4 & -8.13 & -5.08 & $2008 \mathrm{~m}_{7}$ \\
\hline Sabit & 4 & -8.12 & -4.80 & $2008 \mathrm{~m}_{7}$ \\
\hline Trend & 4 & -7.76 & -4.42 & $2011 \mathrm{~m}_{11}$ \\
\hline \multicolumn{5}{|l|}{$\Delta \mathbf{e}_{\mathrm{t}}$} \\
\hline Trend ve Sabit & 2 & -13.80 & -5.08 & $2001 \mathrm{~m}_{11}$ \\
\hline Sabit & 2 & -13.97 & -4.80 & $2001 \mathrm{~m}_{11}$ \\
\hline Trend & 2 & -12.14 & -4.42 & $2007 \mathrm{~m}_{2}$ \\
\hline \multicolumn{5}{|l|}{$\Delta \mathbf{y}_{\mathbf{t}}$} \\
\hline Trend ve Sabit & 0 & -29.84 & -5.08 & $2009 \mathrm{~m}_{4}$ \\
\hline Sabit & 0 & -29.82 & -4.80 & $2009 \mathrm{~m}_{12}$ \\
\hline Trend & 0 & -29.64 & -4.42 & $2011 \mathrm{~m}_{2}$ \\
\hline
\end{tabular}

Not: Gecikme uzunlukları TTest aracılığı ile bulunmuştur.

Tablo 4: Clemente, Montanes ve Reyes Test Sonuçları

\begin{tabular}{|c|c|c|c|c|}
\hline \multirow{2}{*}{ Değişken } & Model & $\begin{array}{c}\text { Minimum T- } \\
\text { Stat }\end{array}$ & \%5 Kritik Değer & Kirılma Yılları \\
\hline \multirow{3}{*}{$\Delta \mathbf{p}_{\mathbf{t}}$} & Trend (AO) & -9.72 & -5.49 & $2001 \mathrm{~m}_{2}, 2003 \mathrm{~m}_{1}$ \\
\cline { 2 - 5 } & Trend ve Sabit (IO) & -11.28 & -5.49 & $2001 \mathrm{~m}_{3}, 2003 \mathrm{~m}_{2}$ \\
\hline \multirow{2}{*}{$\Delta \mathbf{p}_{\mathbf{t}} *$} & Trend (AO) & -6.57 & -5.49 & $2008 \mathrm{~m}_{7}, 2009 \mathrm{~m}_{1}$ \\
\cline { 2 - 5 } & Trend ve Sabit (IO) & -6.56 & -5.49 & $2008 \mathrm{~m}_{5}, 2008 \mathrm{~m}_{12}$ \\
\hline \multirow{3}{*}{$\Delta \mathbf{e}_{\mathbf{t}}$} & & & & $2001 \mathrm{~m}_{1}, 2001 \mathrm{~m}_{6}$ \\
\cline { 2 - 5 } & Trend ve Sabit (IO) & -7.99 & -5.49 & $2000 \mathrm{~m}_{12}, 2001 \mathrm{~m}_{9}$ \\
\hline \multirow{2}{*}{$\Delta \mathbf{y}_{\mathbf{t}}$} & Trend (AO) & -6.93 & -5.49 & $2001 \mathrm{~m}_{1}, 2008 \mathrm{~m}_{10}$ \\
\cline { 2 - 5 } & Trend ve Sabit (IO) & -6.53 & -5.49 & $2001 \mathrm{~m}_{2}, 2008 \mathrm{~m}_{11}$ \\
\hline
\end{tabular}


Tablo 5: Geçiş Katsayısı Tahminleri, 1994-2016

\begin{tabular}{|c|c|}
\hline$\Delta p_{t}=\gamma+\sum_{i=0}^{9} a_{i} \Delta e_{t-i}+\sum_{i=0}^{9} b_{i} \Delta p_{t-i}^{*}+c \Delta y_{t}+u_{t}$ & Katsayı Tahminleri \\
\hline$a_{0}$ & $0.220 *$ \\
\hline$a_{1}$ & $0.166^{*}$ \\
\hline$a_{2}$ & $0.032 * *$ \\
\hline$a_{3}$ & $0.078 *$ \\
\hline$a_{4}$ & $0.051 *$ \\
\hline$a_{5}$ & $0.040 * *$ \\
\hline$a_{6}$ & $0.083 *$ \\
\hline$a_{7}$ & $0.031 *$ \\
\hline$a_{8}$ & $0.062 *$ \\
\hline$a_{9}$ & $0.060^{*}$ \\
\hline${\text { Düzeltilmiş } \mathbf{R}^{2}}^{2}$ & 0.672 \\
\hline Kısa Dönem Geçiş Katsayısı, $a_{0}$ & Uzun Dönem Geçiş Katsayısı, $\sum_{i=0}^{9} a_{i}$ \\
\hline $0.220^{\dagger}$ & $0.823^{\bullet}$ \\
\hline
\end{tabular}

Not: * ve ** işaretleri katsayıların sırasıyla \% 5 ve \% 10 hata düzeylerinde anlamlı olduğunu göstermektedir. Regresyon tahmin edilirken, otokorelasyon ve eşvaryans varsayımı altında varyans-kovaryans matrisinde düzeltme yapan Newey-West standart hataları kullanılmıştır. Newey-West standart hatalarının hesaplanması seçilen maksimum gecikme sayısına göre değişecektir. Burada, gecikme sayısı (L) belirlenirken Stock ve Watson (2012)'ın önerisi takip edilmiş ve $\mathrm{L}=0.75 \mathrm{~T}^{1 / 3} \approx 5$ olarak hesaplanmıștır. $\mathrm{T}$ ise regresyonda kullanılan veri sayısıdır. †ve , \% 10 hata payı ile esnekliklerin sırasıyla " 0 " ve " 1 " den farklı olduklarını ifade etmektedir.

Tablo 5, Campa ve Goldberg (2005) tarafindan önerilen modelden elde edilen kısa ve uzun dönem geçiş katsayıları tahmin sonuçlarını vermektedir. Tablo 5'deki değerler tahmin edilirken, 3 çeyreklik yani dokuz aylık gecikme uzunluğu kullanılmıştır ${ }^{4}$. Bununla birlikte, LCP hipotezi geçiş katsayısının "0" olduğu yokluk hipotezini temsil ederken; PCP hipotezi, geçiş katsayısının "1" olduğu yokluk hipotezini temsil etmektedir ${ }^{5}$. Tablo 5 yardımıyla elde edilen sonuçlar şu şekilde özetlenebilir:

1) Kısa dönemde geçiş katsayısı 0.22 olarak bulunurken, uzun dönemde bu oran 0.82 olmuştur. Yani, \% 1'lik bir döviz kuru şokunun yurtiçi fiyatlara geçişi bir aylık kısa dönemde \% 0.22 olarak gerçekleşirken dokuz aylık uzun dönemde \% 0.82 olarak gerçekleşmiştir. Döviz kurundaki değişimlerin fiyatlar üzerindeki etkisi özellikle ilk iki ayda oldukça büyük olmakta sonraki aylarda ise nispeten daha

\footnotetext{
${ }^{4}$ Model tahmin edilirken, literatüre uygun olarak gecikme sayısı için sırasıyla $n=9$ ve $n=12$ değerleri seçilmiştir, yani sırasıyla üç ve dört çeyreklik gecikme uzunlukları kullanılmıştır. Ancak, döviz kurlarındaki değişimden kaynaklanan geçiş katsayıları özellikle ilk gecikmelerden kaynaklandığından, $n=12$ iken elde edilen kısa ve uzun dönem değerler ile $n=9$ iken elde edilen kısa ve uzun dönem değerler arasında önemli bir fark gözlemlenmemiştir. Daha açık ifade etmek gerekirse, $\mathrm{n}=12$ iken kısa dönem geçiş katsayısı, $a_{0}=0.216$ iken uzun dönem geçiş katsayısı, $\sum_{i=0}^{12} a_{i}=0.818$ olarak bulunmuştur. Elde edilen sonuçlar $\mathrm{n}=9$ iken elde edilen sonuçlar ile çok benzer olduğundan, tahmin sonuçları rapor edilirken gecikme uzunluğunun dokuz olarak kullanılması tercih edilmiștir.

${ }^{5}$ Teorik olarak geçiş katsayıları birden büyük olabilir; ancak bu katsayıların "0" ile " 1 " arasında olmasını sağlayacak şekilde sınır koymak mümkündür. Bu durumda tahmin edilen değerlerin standart hataları da düzeltilmelidir. Bunun için Campa ve Goldberg (2005), Fischer dönüşümünü önermişlerdir. Bu çalışmada ise böyle bir dönüşüme gerek görülmemiştir; çünkü kısa ve uzun dönemdeki tüm tahminler sıfır ve bir arasında gerçekleşmiştir.
} 
düşük olmaktadır. Döviz kuru şokunun fiyatlara geçişinin yaklaşık yarısı ilk çeyrekte tamamlanmaktadır.

2) Türkiye için LCP veya PCP hipotezlerinin ya da kısmi geçiş etkisinin geçerli olup olmadığını test etmek için Wald testi kullanılmış ve geçiş katsayılarının 0 veya 1 olduğunu ifade eden yokluk hipotezleri hem kısa hem de uzun dönem için reddedilmiştir. Dolayısıyla Türkiye için tam geçiş veya sıfır geçiş etkisinden bahsedilemez. Diğer bir deyişle, 1994-2016 yılları arasında Türkiye için kısmi geçiş etkisinin varlığından söz edilebilir.

Bununla birlikte, sonuçların tutarlılığını kontrol etmek için regresyon (1), tek gecikmeli $\Delta \mathrm{p}_{\mathrm{t}}$ kontrol değişkeni eklenerek tahmin edilecektir. Bu işlem sadece istatistiki amaçlı olmayıp, Edwards (2006)'1 takiben enflasyon hedeflemesi uygulaması ile birlikte enflasyon ataletinin azalıp azalmadığını analiz edebilmeye de yarayacaktır. Literatürde "enflasyon ataleti", cari enflasyon oranının, iktisadi karar birimlerinin önceki dönem enflasyon beklentilerini sürdürmeleri nedeniyle düşmeme yönünde direnç göstermesi olarak tanımlanabilir. Tablo 6' de yer alan pozitif ve istatistiki olarak anlamlı $\mathrm{d}_{1}=0.294$ katsayısı, Türkiye için 1994-2016 döneminde enflasyon ataletinin olduğunu ifade etmektedir. Ayrıca, elde edilen kısa ve uzun dönem katsayı tahminleri Tablo 5'de yer alan kısa ve uzun dönem katsayılarına oldukça yakındır.

Tablo 6: Enflasyon Ataleti ve Geçiş Katsayısı Tahminleri, 1994-2016

\begin{tabular}{|c|c|}
\hline $\begin{array}{c}\Delta p_{t}=\gamma+\sum_{i=0}^{9} a_{i} \Delta e_{t-i}+\sum_{i=0}^{9} b_{i} \Delta p_{t-i}^{*}+c \Delta y_{t} \\
+d_{1} \Delta p_{t-1}+u_{t}\end{array}$ & Katsayı Tahminleri \\
\hline$a_{0}$ & $0.219 *$ \\
\hline$a_{1}$ & $0.113^{*}$ \\
\hline$a_{2}$ & $0.046^{*}$ \\
\hline$a_{3}$ & $0.114 *$ \\
\hline$a_{4}$ & $0.053^{*}$ \\
\hline$a_{5}$ & $0.041 * *$ \\
\hline$a_{6}$ & $0.092 *$ \\
\hline$a_{7}$ & 0.021 \\
\hline$a_{8}$ & $0.072 *$ \\
\hline$a_{9}$ & $0.064 *$ \\
\hline$d_{1}$ & $0.294 *$ \\
\hline Düzeltilmiş $\mathbf{R}^{2}$ & 0.694 \\
\hline Kısa Dönem Geçiş Katsayısı, $a_{0}$ & $\begin{array}{c}\text { Uzun Dönem Geçiş Katsayısı, } \\
\qquad \sum_{i=0}^{\mathbf{g}} a_{i} \\
\end{array}$ \\
\hline 0.219 & 0.815 \\
\hline
\end{tabular}

Not: * işareti katsayıların \% 5 hata düzeylerinde anlamlı olduğunu göstermektedir. Regresyon tahmin edilirken, otokorelasyon ve eşvaryans varsayımı altında varyans-kovaryans matrisinde düzeltme yapan Newey-West standart hataları kullanılmıştır. Uzun dönemli geçiş katsayısı hesaplanırken, istatistiki olarak anlamsız a katsayısı dışarıda bırakılmıştır. 
Tablo 7 ise ÜFE endeksi kapsamındaki sanayi kollarındaki kısa ve uzun dönem geçiş katsayılarını göstermektedir. Maden ve enerji sektörlerindeki geçiş katsayıları hem kısa hem de uzun dönemde birbirine yakınken, imalat sektörüne ait kısa ve uzun dönem geçiş katsayıları diğer iki sektörden biraz daha yüksektir. Bununla birlikte, alt sektörlerde de kısa dönemde kısmi geçiş sözkonusu iken, uzun dönemde enerji sektöründe tam geçiş sözkonusudur ve PCP hipotezi reddedilememiştir. Bunun nedeni ise muhtemelen Türkiye'nin özellikle enerji sektöründeki dışa bağımlılığıdır. Diğer bir değişle, enerji sektöründeki dışa bağımlılık nedeniyle bu sektöre yerel yeni firmaların girmesi pek mümkün değildir ve Türkiye'ye ihracat yapan firmaların bu yeni girişleri önleyebilmek için kar marjlarını uyarlayıp döviz kurundaki değişimleri aynı oranda yerel fiyatlara yansıtmama gibi bir stratejiye başvurmalarına gerek yoktur. Dolayısıyla, tek fiyat kanununa uygun olarak, nominal döviz kurundaki değişmeler Türkiye'deki enerji fiyatlarına tam olarak yansıyabilecektir.

Tablo 7: ÜFE Kapsamındaki Sanayi Kollarına Ait Geçiş Katsayıları, 1994-2016

\begin{tabular}{|c|c|c|}
\hline Sanayi Alt Kolları & Kısa Dönem Geçiş Katsayısı & $\begin{array}{c}\text { Uzun Dönem Geçiş } \\
\text { Katsayısı }\end{array}$ \\
\hline Maden & $0.228^{\dagger^{\bullet}}$ & $0.739^{{ }^{\bullet}}$ \\
\hline İmalat & $0.302^{\dagger^{\bullet}}$ & $0.840^{{ }^{\bullet}}$ \\
\hline Enerji & $0.234^{\dagger^{\bullet}}$ & $0.783^{\dagger}$ \\
\hline
\end{tabular}

Not: ${ }^{\dagger}$ ve,$\% 10$ hata payı ile sanayinin tüm altkolları için, esnekliklerin sırasıyla " 0 " ve "1" den farklı olduğunu ifade etmektedir. Dickey-Fuller (1979) ve Phillips-Perron (1989) testlerine göre, maden, imalat ve enerji fiyat indekslerindeki değişmelerin birim köke sahip olduklarını söyleyen yokluk hipotezi \% 5 hata payı ile reddedilmiştir.

\section{B.Enflasyon Hedeflemesi ve Geçiş Katsayıları}

Buraya kadar yapılan analizlerde, esneklik katsayıları tahmin edilirken, 1994-2016 dönemi boyunca aynı para politikası stratejisi uygulanmış gibi hareket edilerek tüm dönem için ortalama geçiş katsayıları elde edilmiştir. Ancak, modelden tahmin edilen katsayılar yapısal olmadığında, muhtemel strateji değişiklikleri tahmin edilen parametrelerde önemli bir değişime yol açabilecektir. Türkiye örneğine baktığımız da ise, fiyatlar genel düzeyi açısından 2006 yılı oldukça büyük bir öneme sahiptir ve para politikası stratejisi olarak açık enflasyon hedeflemesine geçilmiştir. Özellikle, döviz kuru ve parasal büyüklüklerin ana hedef olarak kullanılmasının fiyat istikrarını sağlamada başarısız olması, dünyada başarılı örnekleri bulunan enflasyon hedeflemesi stratejisini Türkiye için ön plana çıkarmıştır. Dolayısıyla, açık enflasyon hedeflemesinin uygulanmadığı 1994-2006 dönemi boyunca elde edilen geçiş katsayılarının, bu stratejinin uygulandığı 20062016 yılları arasında da benzer olacağını iddia etmek rasyonel olmayabilecektir. $\mathrm{Bu}$ bölümde, uygulanan enflasyon hedeflemesi staratejisinin fiyatlar üzerindeki olumlu etkisi gözönüne alınarak, söz konusu stratejinin geçiş katsayılarında, diğer bir deyişle model parametrelerinde nasıl bir değişme yarattığ 1 sorusuna cevap aranacaktır. 
Bu amaçla, enflasyon hedeflemesi ile birlikte geçiş katsayılarındaki olası değişimi görebilmek için örneklem periyodu ikiye ayrılacaktır. İlk periyot 1994:m - $^{-}$ 2005: $\mathrm{m}_{12}$ dönemini kapsarken, ikinci periyot açık enflasyon hedeflemesinin başladığı 2006: $\mathrm{m}_{1}$ ile başlayıp 2016:m9 dönemi ile son bulacaktır.

Tablo 8: Enflasyon Hedeflemesi Öncesi ve Sonrası geçiş Katsayıları

\begin{tabular}{|c|c|c|}
\hline \multirow{2}{*}{$\begin{array}{c}\Delta p_{t}=\gamma+\sum_{i=0}^{9} a_{i} \Delta e_{t-i}+\sum_{i=0}^{9} b_{i} \Delta p_{t-i}^{*} \\
+c \Delta y_{t}+u_{t}\end{array}$} & \multicolumn{2}{|c|}{ Katsayı Tahminleri } \\
\hline & 1994:m $1-2005: m_{12}$ & 2006:m $1-2016: m_{9}$ \\
\hline$a_{0}$ & $0.199 *$ & $0.161^{*}$ \\
\hline Düzeltilmiş $\mathbf{R}^{2}$ & 0.595 & 0.550 \\
\hline \multicolumn{3}{|l|}{ Geçiş Katsayları } \\
\hline Kısa Dönem & $0.199^{\dagger}$ & $0.161^{\dagger}$ \\
\hline Uzun Dönem, $\sum_{i=0}^{9} a_{i}$ & $0.639^{\dagger}$ & $0.280^{\dagger}$ \\
\hline
\end{tabular}

Not: * işareti katsayıların sırasıyla \%5 hata düzeyinde anlamlı olduğunu göstermektedir. Regresyon tahmin edilirken, otokorelasyon ve eşvaryans varsayımı altında varyans-kovaryans matrisinde düzeltme yapan NeweyWest standart hataları kullanılmıştır. ${ }^{\dagger}$ ve,$\% 10$ hata payı ile esnekliklerin sırasıyla " 0 " ve " 1 " den farklı olduğunu ifade etmektedir.

Tablo 8, kısa ve uzun dönem geçiş katsayılarının enflasyon öncesi ve enflasyon sonrası dönemdeki tahminlerini vermektedir. Tablodan görüleceği üzere, kısa ve uzun dönem katsayıları enflasyon hedeflemesi ile birlikte azalmıştır. Türkiye'de enflasyon hedeflemesi öncesinde döviz kurundaki yüzde 1'lik bir artış (ki bu çalışmada ulusal paranın \%1 kadar değer kaybettiğini ifade etmektedir), ÜFE üzerinden yurtiçi fiyatları uzun dönemde yüzde 0.64 kadar arttırırken, enflasyon hedeflemesi sonrası bu oran azalmış ve yüzde 0.28 olmuştur. Ayrıca, her iki dönemde de LCP ve PCP hipotezleri reddedilmiştir.

Tablo 9 ise enflasyon ataletinin enflasyon hedeflemesi öncesi ve sonras1 nasıl değiştiğini göstermektedir. Enflasyon ataletini gösteren $\mathrm{d}_{1}$ katsayısı enflasyon hedeflemesi öncesi 0.363 olup istatistiksel olarak anlamlı iken, enflasyon hedeflemesi sonrası bu katsayı yine anlamlı olup 0.160 olarak gerçekleşmiştir. Bu da enflayon hedeflemesinin enflasyon ataletini gidermede başarılı olduğunu göstermektedir. Enflasyon hedeflemesi ile birlikte, TCMB'nin artan bağımsızlılığına ve güvenilirliliğine paralel şekilde karar birimlerinin beklentilerinin doğru şekilde yönetilmesi ve tüm bunların sonucunda fiyatların döviz kuruna endekslenmesi davranışının kırılmasına ek olarak enflasyon ataletinin de azalması, geçiş katsayılarındaki düşmenin nedenini ortaya koymaktadır. Enflasyon ataletindeki azalma, enflasyon katılığını azaltacağından dolayı geçiş katsayılarının düşmesine yardımcı olabilecektir. Son olarak, Tablo 8'den elde edilen sonuçlara benzer şekilde, esnekliklerin 0 veya 1 olduğunu ifade eden yokluk hipotezleri kısa ve uzun dönem için reddedilmiştir. 
Tablo 9: Enflasyon Ataleti ve Geçiş Katsayısı Tahminleri, Enflasyon Hedeflemesi Öncesi ve Sonras1

\begin{tabular}{|c|c|c|}
\hline \multirow{2}{*}{$\begin{array}{c}\Delta p_{t}=\gamma+\sum_{i=0}^{9} a_{i} \Delta e_{t-i}+\sum_{i=0}^{9} b_{i} \Delta p_{t-i}^{*}+c \Delta y_{t} \\
+d_{1} \Delta p_{t-1}+u_{t}\end{array}$} & \multicolumn{2}{|c|}{ Katsayı Tahminleri } \\
\hline & 1994:m1-2005:m 12 & 2006:m1-2016:m9 \\
\hline$a_{0}$ & $0.205^{*}$ & $0.163 *$ \\
\hline$d_{1}$ & $0.363^{*}$ & $0.160 *$ \\
\hline Düzeltilmiș $\mathbf{R}^{2}$ & 0.635 & 0.557 \\
\hline Geçiş Katsayları & & \\
\hline Kısa Dönem & $0.195^{+\bullet}$ & $0.163^{+\bullet}$ \\
\hline Uzun Dönem & $0.631^{\bullet \bullet}$ & $0.255^{\bullet}$ \\
\hline
\end{tabular}

Not: * işareti katsayıların sırasıyla \% 5 hata düzeyinde anlamlı olduğunu göstermektedir. Regresyon tahmin edilirken, otokorelasyon ve eşvaryans varsayımı altında varyans-kovaryans matrisinde düzeltme yapan NeweyWest standart hataları kullanılmıştır. "ve , \% 10 hata payı ile esnekliklerin sırasıyla " 0 " ve "1" den farklı olduğunu ifade etmektedir.

Tablo 10: ÜFE Kapsamındaki Sanayi Kollarına Ait Geçiş Katsayıları, Enflasyon Hedeflemesi Öncesi ve Sonrası

\begin{tabular}{|c|c|c|c|c|}
\hline \multirow[b]{2}{*}{$\begin{array}{l}\text { Sanayi Alt } \\
\text { Kollari }\end{array}$} & \multicolumn{2}{|c|}{ 1994:m $1-2005: m_{12}$} & \multicolumn{2}{|c|}{ 2006:m1-2016:m9 } \\
\hline & $\begin{array}{c}\text { Kısa Dönem } \\
\text { Geçiş Katsayısı }\end{array}$ & $\begin{array}{c}\text { Uzun Dönem } \\
\text { Geçiş Katsayısı }\end{array}$ & $\begin{array}{c}\text { Kısa Dönem } \\
\text { Geçiş Katsayısı }\end{array}$ & $\begin{array}{c}\text { Uzun Dönem } \\
\text { Geçiş Katsayısı }\end{array}$ \\
\hline Maden & $0.239^{{ }^{\bullet}}$ & $0.689^{{ }^{\bullet}}$ & $0.080^{\dagger}$ & $0.240^{\bullet}$ \\
\hline İmalat & $0.301^{\dagger}$ & $0.717^{\bullet}$ & $0.216^{\dagger}$ & $0.303^{\dagger^{\bullet}}$ \\
\hline Enerji & $0.137^{\dagger^{\bullet}}$ & $0.580^{\dagger}$ & $0.338^{\dagger \bullet}$ & $0.326^{\dagger^{\bullet}}$ \\
\hline
\end{tabular}

Not: ${ }^{\dagger}$ ve,$\% 10$ hata payı ile sanayinin tüm altkolları için, esnekliklerin sırasıyla "0" ve " 1 " den farklı olduğunu ifade etmektedir.

Tablo 10, sanayi alt kollarında enflasyon hedeflemesi ile birlikte nasil bir değişim yaşandığını göstermektedir. Beklenildiği gibi, enflasyon hedeflemesi ile birlikte tüm esneklik katsayıları (kısa dönemde enerji sektörü hariç) azalma eğilimine girmiştir. Ayrıca PCP ve LCP hipotezleri, tüm sektörler için hem enflasyon hedeflemesi öncesi dönemde hem de enflasyon hedeflemesi sonrasi dönemde reddedilmiştir. Dolayısıyla, Türkiye'de ÜFE kapsamındaki alt sektörler bakımından da fiyatların döviz kurundaki değişmelere kısmi uyarlaması sözkonusudur. Dikkat edilirse, LCP ve PCP hipotezleri ile ilgili Tablo 10'dan elde edilen sonuçlar Tablo 7'den elde edilen sonuçlara oldukça yakındır. Tek fark, 19942016 dönemini kapsayan veri seti için enerji sektöründe PCP reddedilemezken, enflasyon hedeflemesine geçilmesi ile birlikte modeldeki parametrelerde olası değişim gözönüne alındığında enerji sektöründe PCP hipotezi de reddedilmektedir. Aslında bu beklenmeyen bir sonuç değildir; çünkü, enflasyon hedeflemesi ile birlikte kısa ve uzun dönem katsayılar göreceli olarak bir yerine sıfıra yakın çıkma eğilimine girmişlerdir. Son olarak, enflasyon hedeflemesi ile birlikte döviz kurundaki şokların enerji fiyatları üzerindeki etkisi, hem kısa hem de uzun dönemde imalat ve madencilik sektörlerinden daha yüksek olmuştur. 


\section{SONUÇ}

$\mathrm{Bu}$ çalışmada, Campa ve Goldberg (2005) tarafından önerilen model kullanılarak, 1994:m $\mathrm{m}_{1}$-2016: $\mathrm{m}_{9}$ dönemleri arasında döviz kurlarında meydana gelen şokların nominal döviz kuruna geçiş etkisi Türkiye örneği için test edilmiştir. Türkiye'de enflasyon hedeflemesi öncesinde döviz kurundaki yüzde 1'lik bir artış, ÜFE üzerinden yurtiçi fiyatları uzun dönemde yüzde 0.64 kadar arttırırken, enflasyon hedeflemesi sonrası bu oran azalmış ve yüzde 0.28 olmuştur. Elde edilen bu sonuç, literatürdeki genel eğilime paralel olarak, enflasyon hedeflemesine geçilmesi ile birlikte döviz kurlarında meydana gelen şokların yurtiçi fiyatlara olan etkisinin azaldığını göstermektedir. Ayrıca, enflasyon hedeflemesi öncesi ve sonrasında, hem kısa hem de uzun dönemde LCP ve PCP hipotezleri reddedilmiştir. Enflasyon hedeflemesinin başladığı 2006 yılından günümüze kadar, döviz kurlarındaki şokların fiyatlara etkisi ise en çok enerji sektöründe görülmektedir. Son olarak, Türkiye'de 1994-2016 dönemleri arasında bir enflasyon ataleti olduğu ve bunun da enflasyon hedeflemesi ile birlikte azaldığı sonucuna ulaşılmışırır.

Enflasyon hedeflemesi stratejisine geçiş ile birlikte geçiş katsayılarında meydana gelen azalmanın nedeni ise muhtemelen TCMB'nin artan güvenilirliği sayesinde beklentilerin doğru şekilde yönetilmesine paralel olarak, enflasyon ataletinin ve yurtiçi fiyatların döviz kuruna endekslenme davranışının kırılmaya başlanmasıdır. Enflasyon ataletinin ve endekslemenin kırılmasında çok önemli bir role sahip olan merkez bankası bağımsızlığının kaybedildiğine dair kamuoyunda oluşacak olası bir izlenim ise, enflasyon hedeflemesinin geçiş katsayıları üzerindeki olumlu etkisini ortadan kaldırabilecektir. Dolayısıyla TCMB, bağımsız olduğuna dair kararlı açıklamalar yapmalı, daha da önemlisi nihai hedefi olan fiyat istikrarını sağlamada para politikası araçlarını ve yöntemlerini siyasi veya herhangi bir otoritenin onayına bağlı kalmadan kullanabilmede 1srarc1 olmalı, kamuoyu üzerinde TCMB'nin bağımsızlığını zedeleyici hiçbir uygulamada bulunmamalıdır. TCMB tarafından ekonomideki karar alıcıların üzerinde başarı ile oluşturulacak bu güçlü bağımsızlık algısı ise döviz kuru değişimlerinden kaynaklanan yutiçi fiyatlar genel düzeyinin artmamasını sağlamada önemli bir rol üstlenecektir.

\section{KAYNAKÇA}

Akaike, H. (1973). Information Theory and an Extension of the Maximum Likelihood Principle Second International Symposium on Information Theory. Budapest: Academiai Kiado.

Alptekin, V., Yılmaz, K.Ç., Taş, T. (2016). Döviz Kurundan Fiyatlara Geçiş Etkisi: Türkiye Örneği. Selçuk Üniversitesi Sosya Bilimler Enstitüsü Dergisi, 35. 1-9

Altıntaş, H. (2014). Türkiye'de Döviz Kurunun Enflasyon Üzerine Geçiş Etkisinin Ekonometrik Analizi: 1987-2011. Uludağ Üniversitesi İIBF Dergisi, 33(1), 163-201.

Arslaner, F., Karaman, D., Arslaner, N., Kal, S.H. (2014). The Relationship between Inflation Targeting and Exchange Rate Pass-Through in Turkey with a Model Averaging Approach (No:14/16). Central Bank of the Republic of Turkey Working Paper.

Bayat, T., Özcan, B., Taş, Ş. (2015). Türkiye'de Döviz Kuru Geçiş Etkisinin Asimetrik Nedensellik Testleri ile Analizi. Eskişehir Osmangazi Üniversitesi İibf Dergisi, 10(2), 7- 30

Campa, J., Goldberg, L. (2005). Exchange Rate Pass-Through into Import Prices. The Review of Economics and Statistics, 87(4), 679-690 
Choudhria, E. U., Hakura, D.S. (2006). Exchange Rate Pass-Through to Domestic Prices: Does The Inflationary Environment Matter? Journal of International Money and Finance, 25(4), 614639.

Clemente, J., Montanes, A., Reyes, M. (1998), Testing for a Unit Root in Variables with a Double Change in the Mean, Economics Letters, 59 (2):175-182.

Dickey, D. A., Fuller, W. A. (1979). Distribution of the Estimators for Autoregressive Time Series with a Unit Root. Journal of the American Statistical Association, 74(366), 427-431.

Edwards, S. (2006). The Relationship Between Exchange Rates and Inflation Targeting Revisited (Working Paper, No. 12163). Cambridge: Massachusetts, National Bureau of Economic Research.

Ergin, A. (2015). Döviz Kuru Ve Enflasyon Arasindaki Geçiş Etkisi: Türkiye Örneği. Ömer Halisdemir Üniversitesi İktisadi ve İdari Bilimler Fakültesi Dergisi, 8(3), 13-29

Gagnon, J.E., Ihrig, J. (2004). Monetary Policy and Exchange Rate Pass-Through. International Journal of Finance and Economics, 9(4): 315-38.

Ghosh, A., Rajan, R. S. A. (2007). Survey of Exchange Rate Pass-Through in Asia. Asian-Pacific Economic Literature, 21(2), 13-28

Goldberg, K., Knetter, M. (1997). Goods Prices and Exchange Rates: What Have We Learned? Journal of Economic Literature, 35(3), 1243-1272.

Ito, T., Sato, K. (2007). Exchange Rate Pass-Through and Domestic Inflation: A Comparison between East Asia and Latin American Countries (No:07040). RIETI Discussion Paper Series.

Jiang J., Kim, D. (2013), Exchange Rate Pass-Through to Inflation in China. Economic Modelling, 33, 900-912.

Junior, R.P.N. (2007). Inflation Targeting and Exchange Rate Pass-Through. Brazilian Journal of Applied Economics, 11(2),189-208

Kara, H., Ögünç, Fethi. (2008). Inflation Targeting and Exchange Rate Pass-Through: The Turkish Experience. Emerging Markets Finance \& Trade, 44(6), 52-66.

Kara, H., Öğünç, F. (2012). Döviz Kuru ve İthalat Fiyatlarının Yurt İçi Fiyatlara Etkisi. İktisat İşletme ve Finans, 27(317), 9-28.

Leigh, D., Rossi, M. (2002). Exchange Rate Pass-Through in Turkey (No: WP/02/204), International Monetary Fund Working Paper.

Masha, I., Park, C. (2012). Exchange Rate Pass Through to Prices in Maldives (No: WP/12/126). International Monetary Fund Working Paper.

McCarthy, J. (2007). Pass-Through of Exchange Rates and Import Prices to Domestic Inflation in Some Industrialized Economies. Eastern Economic Journal, 33(4), 511-537.

Mujica, P., Saens, R. (2015). Exchange Rate Pass-Through and Inflation Targets in Chile. Cepal Review, 117, 137-146

Phillips, P. C. B., Perron P. (1988). Testing for a Unit Root In Time Series Regression. Biometrika 75(2),335-346.

Stock J. H., Watson M. W. (2012). Introduction to Econometrics. Boston: Pearson.

Sweidan., O.D. (2013). Exchange Rate Pass-Through into Import Prices in Jordan, Global Economy Journal. 13(1), 109-128.

Taylor J. (2000). Low Inflation, Pass-Through, and Pricing Power of Firm. European Economic Review, 44(7), 1389-1408.

Tekin, B.R., Yazgan, M.E. (2009). Exchange Rate Pass-Through in Turkish Export And Import Prices. Applied Economics, 41, 2221-2228.

Volkan, A., Saatçioğlu, C., Korap, L. (2007). Impact Exchange Rates on Domestic Inflation: The Turkish Experience (No:6). Turkish Economic Association Discussion Paper.

Zivot, E., Andrews, D.W.K. (1992). Further Evidence on the Great Crash, the Oil-PriceShock, and the Unit-Root Hyphothesis. Journal of Business \& Economic Statistics, 10(3), 251-270. 


\section{SUMMARY}

The main purpose of this study is to investigate the exchange rate passthrough into domestic prices (in terms of producer price index - PPI) in the case of a small emerging open market economy such as Turkey before and after the adoption of inflation targeting regime. The data in the study cover the period of 1994: $\mathrm{m}_{1}$ and 2016: $\mathrm{m}_{9}$. This study employs the model proposed by Campa and Goldberg (2005).

At the very first stage, exchange rate pass-through coefficients on both general domestic prices and the prices of industrial sub-sectors such as mining, manufacturing and energy are investigated during the entire sample period. The empirical findings first reveal that short run and long run pass-through coefficients are about 0.22 and 0.82 , respectively. The test results also show that Turkey was exposed the inflation inertia during the whole sample period. On the other hand, while the passthrough coefficients of the mining and energy sectors are very close to each other in both short and long run, the pass-through coefficients of the manufacturing sector are slightly higher than the other two sectors. In the short run, there is a partial passthrough in the sub-sectors, whereas energy sector has complete pass-through in the long run. That is, PCP (producer currency pricing) hypothesis for the energy sector has not been able to rejected with the possible reason of Turkey's massive dependence on the foreign energy market.

At the second stage of the study, the sample period is divided into two subperiods in order to be able to show the possible changes of the pass-through coefficients in parallel with the adoption of inflation targeting. The first data period covers 1994: m1-2005: m12, while the second data period covers the period of 2006: $\mathrm{m} 1$ (the beginning of the (open) inflation targeting) and 2016: $\mathrm{m} 9$. After the adoption of inflation targeting, empirical findings first reveal that pass-through from exchange rates to domestic prices has substantially weakened. Before the adoption of inflation targeting, a one percent increase in the exchange rates raises the domestic prices 0.64 percent in the long run. However, this rate has substantially weakened after the adoption of inflation targeting, and now a one percent increase in the exchange rates raises the domestic prices 0.28 percent in the long run. Second, the validity of LCP (local currency pricing) and PCP hypotheses are both rejected before and after the adoption of inflation targeting. Third, the impact of exchange rate shocks on energy prices has been higher than in the manufacturing and mining sectors both in the short and long run during the inflation targeting. Finally, a more inflationary-focused monetary policy helps to reduce the inflation inertia in Turkey.

The possible reasons for the significant decline in the pass-through coefficients with the adoption of inflation targeting are likely to be both the decreasing of the inflation inertia and weakening of the economic agents' behavior of indexing the domestic prices into the foreign exchange rate due to the increased credibility of the CBRT and its proper management of expectations during the inflation targeting period. 